\title{
The Classification and Utility of Video Resources in Higher Vocational Education
}

\author{
Yongpei Ye \\ Shenzhen Polytechnic, Shenzhen,China \\ yeyp@szpt.edu.cn
}

\begin{abstract}
Keywords: Education, Higher Vocational Education, Practical Teaching, Video Resources, Construction and Utility
\end{abstract}

\begin{abstract}
The practical teaching in this paper refers to the teaching along with training in Higher Vocational Education. Video resources play a very important role in cultivating students' vocational quality, job ability, basic skills, and application competency. Video resources are not only a means of making teaching intuitive and vivid, but also an important frame of references for self-learning. For many years, Shenzhen Polytechnic has come up with creative ideas and strategies to build video resources at levels such as materials, curriculums, and majors. Through the public platform, video resources are mutually shared in the area, thus strengthening practical teaching, and providing innovational pathways for construction and sharing of video resources in Higher Vocational Education.
\end{abstract}

\section{Foreword}

Video resources are a kind of form of teaching media which can present teaching contents and teaching methods effectively. Video resources have some advantages and characteristics that print media, images, animation and other general media do not have [1]. In recent years, the domestic demand of video resources is enlarging driven by the construction of excellent courses, foreign video open courseware introduced, the development of distance education and other factors. Under the guidance of the policy of Ministry of Education, many universities and colleges are making video resources. Shenzhen Polytechnic has constructed a data bank of video resources at three different levels including the material level, the curriculum level and the major level. This can meet the needs of the teaching practice for different subject categories. Under this foundation, we have been exploring the mode to share video resources in order to promote the construction of video resources in teaching, increase the utility rate of video resources, and improve the teaching level in higher vocational education.

\section{The Classification Construction on Video Resources}

The construction of such video resources should reflect the training aim, emphasize the technical application ability and carry out the demand of the training target in higher vocational education[1]. With the experience of the construction of such video resources from different curriculum and disciplines in Shenzhen Polytechnic in the past years, we have gradually explored the method of making such video resources at three levels. Besides, we have came up with creative ideas and strategies in effectiveness, advancement and representativeness, usefulness and comprehension, which is suitable for different subject categories in higher vocational institutions such as engineering, medical sciences, practice courses , art designs and production, etc.

\subsection{Vertical Classifications on Video Resources}

\subsubsection{The material level video resources}

The video resources at the material level refer to the materials from the unit of curriculums and key points, and difficulties of the curriculum. Video resources are a type of fragments. There is no titles, no ends and no commentary, but an imagery piece of material which is focused on a problem to assist teachers to break through thorny points, highlighting the important contents that teachers need to explain when they present these materials. This kind of video materials takes only tens of seconds or one or two minutes .However, it is a very valuable imagery material in classroom teaching ,very helpful for students to understand the knowledge, also helps to improve teaching quality and efficiency.

\subsubsection{The curriculums level video resources}

The video resources at the course level are the focus of the construction and are the basis of the major video resources. Core courses from a major with distinctive technicality, utilities and comprehensiveness are chosen to make video resources. The key points and difficulties from core courses are chosen to make video resources in order to assist teaching and help students to understand .There are also three-levels at curriculum level video resources. The first level is the basic knowledge and skills training. The second level is improvement training. The third is the training of comprehensiveness and occupation qualification certification. These multi-level video resources cover the basic training, practical and comprehensive training form. The constructions of 
video resources are made by one project as a unit. These multi-level video resources can meet the teaching practice in classroom teaching, but also for students' autonomy, cooperation, inquiry learning and occupation qualification training. They are versatile and applicable not only can be used in one university, but also in other domestic institutions with similar majors, and obtaining better teaching effect.

\subsubsection{Major level video resources}

The video resources at the major level are a collection of the video resources at the material and course level. The set of all courses level video resources constitute the major level video resource databank. No matter what levels of video resources should be actively trying to build the university-enterprise cooperation form. The enterprise personnel participate in the construction of video resources directly or provide enterprise's real cases and materials, or cooperation with industry associations to build video resources for occupation qualification skills training and identify together.

\subsection{Horizontal Classification on Video Resources \\ 2.2.1. Video resources for engineering specialties}

As for the engineering specialty, the practical teaching goal is to train students corresponding professional occupation ability and application ability through a mastery of the application standard, skills, technology and process etc. The training project can be divided into many small programs, each program is relatively independent, which is conducive to the practical teaching and assessment, and facilitate students' independent learning. The description form of practical teaching film should be skill teaching piece and scene teaching piece or the combination of both. The video resources constructions are mainly to the material, curriculum and major levels. For example, there are three modules for CAD/CAM specialty including the basic skills training, professional skills training, comprehensive skills and technical application training. Each module consists of a plurality of training project. The practical teaching film of each training project is relatively independent. The professional skills training module consists of the CNC lathe programming operation, CNC milling machine, machining center programming electric cutting, machining and mold assembly and debugging practical training. Therefore students can learn every part independently. These three modules consist of the CAD/CAM specialty video resources.

\subsubsection{Video resources for the practice specialties}

Practical teaching of this kind of specialty has its own particularity. The main contents are case knowledge, procedural and process knowledge. The constructions of video resources are mainly in the form of scene teaching piece. Teaching contents are demonstrated through various and different roles acting, specific languages, expressions, actions and the relationship between different roles .The construction of video resources are mainly to the curriculum level and major level. A practical teaching film "the bank comprehensive skill training", the location was in the bank simulate laboratory. Students played the different roles such as cashiers, accouters, finance and customers. There were several modules i.e. basic skills module, service module (savings accounts, deposits, withdrawals, transfers and so on) and accounting. The whole practice contents are presented according to the industry business procedures and processes. All these parts consist of the specialty practice video resources.

\subsubsection{Video resources for the art design and production specialties}

This kind of professional training courses has the characteristics both on art designs and product making, which cultivates students' production ability to change their own design ideas to precise model or products and produce the products. The video resources construction of this kind of specialties comes from the collections of teachers and students works mainly at the curriculum level and major level. For example, the practical teaching films both the" Suit Sewing process" and "ceramics making" have design and drawing . Then, the products are manufactured step by step according to the product design intent and the process.

\subsubsection{Video resources for the medical nursing specialties}

The characteristics of this kind of practical teaching are to cultivate the students' practical ability. The video resources are mainly constructed for basic skills training, case teaching and problem solving, clinical teaching in order to train the students' ability of observation, analysis, and problem solving. The form of video resources are in the form of scene teaching pieces and skills teaching pieces. The constructions of video resources are mainly at the material level, curriculum and major level. For example the practical teaching film "optometry technology" has many programs such as objective optometry, optometry, presbyopia table use and so on. These programs help to train students' basic skills and comprehensive skills. Video recourses of teaching film "surgical nursing" are clinical teaching and case teaching. 


\section{How to Realize Video Resources Sharing}

For higher vocational institutions, video resources are the focus of the construction of practical teaching resources. The construction of video resources will promote the reform of practical teaching and high level education resources sharing. Video resources have the characteristics with a large amount of data, strong pertinence, education .The sharing video resources should be have characteristics of regional, subjects, professional expertise, covering a wide range, and can support personalized learning. Currently, video resources have some problems below in construction and sharing.

\subsection{The Problems in Video Resources Construction and Sharing}

3.1.1 The applicability of video resource construction is not unified, mechanism is not perfect

At present, all colleges and universities have made a number of video resources based on their own specialty superiority, strength and teaching characteristics in the region. As video resources are made by different universities independently and depressively, there is no unified planning, no mechanism and no management coordination. The communication and cooperation between the regional colleges and universities are lack of coordination. All these made the construction of video resources having long period, high cost and narrow range. Video resources do not interchangeable and applicable.

\subsubsection{The standards of video resources are not unified}

Currently the high level video resources especially to meet the teaching demand are very scarce. Video resources are produced without relevant technical standards and classification and cataloging norms in some colleges and universities. The classification of video resources is not reasonable without unified management thought and the use of hierarchical storage strategy. Video resources are not compatible in different colleges and universities on different platforms. In addition, video resources are not universal, difficult to achieve the exchange and sharing.

\subsubsection{Video resource content and quality problems}

There are thousands of video resources but the quality of a considerable part of video resources existing is not high and can not meet the needs of teaching in the same specialty of different colleges and universities. The content of video resources can not satisfy teaching reality. There is no pertinence, systematicness and applicability. The content of video resources are scattered, incomplete, and difficult to meet the requirements on the cultivation demand of students' occupation ability, comprehensive quality, occupation quality, basic skills, professional skills and comprehensive application ability of practice teaching. In addition the video resource update time is long leading to the low utilization rate of video resources.

\subsubsection{The evaluation on video resources}

In the construction and application of video resources, "there is no evaluation of the evaluation index system and evaluation of operational feedback management system. There is also no evaluation on the video resources content and quality. The evaluation is not based on scientific, educational, art and technology [2].

\subsubsection{The problem of video resource sharing mode}

Under the current system, more and more colleges and universities develop their own education resource service platform independently. The platform is not designed on its multi-disciplinary and multi-angle. Therefore the video resources are not compatible and can not be shared in different platforms and different colleges and universities The cost of video resources construction is increasing and video resources construction is duplicated.

\subsection{The New Sharing Mode of the Video Resource.}

The sharing mode of video resources is based on the departments of education and all higher vocational colleges as a whole. "Through unified planning, a perfect coordination mechanism has been established to develop regional education resources public platform so as to realize the video resource sharing[3].

\subsubsection{Improve the mechanism and planning of video resources}

In order to ensure the practical teaching video resources building cooperative smoothly and achieve sustainable development in higher vocational colleges. The local authorities should be set up by the education administrative departments, colleges and school authorities[4]. The authority has the responsibility on an overall plan to develop a resource sharing system, improve the operating mechanism of resource sharing, carry out the flexible, diverse and open resources management mode, solve the problems in sharing recourses among different colleges and universities, and improve the evaluation index system of video resources, release video resources co-construction and share information timely. A full account should be taken to solve the problems, including mechanism of video resources co-construction and sharing, sharing mode, intellectual 
property rights, incentive mechanism and quality assessment.

\subsubsection{Follow the specification and standards of resources construction}

The production of video resources must follow the unified technical standards, use universal video resource classification and cataloging standard so as to ensure the sharing of resources at the technical level. At present, the state has formulated a series of related resources construction standards and requirements, such as "education resource construction technical specification" (CELTS-41) and high-quality video open courseware production technical standards. These specification and standards set video resources data elements, production technical standard, the video compression format and technology parameters and provides technical support for the construction of video resources.

\subsubsection{Establish a team for video resources}

It is necessary to establish the university union to make video resources, forming a virtuous circle mechanism of construction and sharing[5]. The team is established by colleges and universities which have subject, professional advantages and regional features, and relevant industries and enterprises. The video resources are built independently or cooperatively. The construction of video resources should make reasonably to, distinguish benefit distribution, and mobilize the enthusiasm of the parties so as to make video resource systemic, extensive and suitable for teaching requirements.

\subsubsection{The evaluation way of video resources}

The scientific evaluation mechanism on video resources is the guarantee to make resources level and quality improving continually [6]. The subjective evaluation of the use of video resource can be evaluated by click rates, the number of download, the evaluation of the user, the network survey and the forum. Meanwhile video resources should be evaluated by expert on scientificalness, education, technology, art and the quality of video resources that can be monitored and the corresponding incentive mechanism is adopted to promote the construction of high-quality video resources.

\subsubsection{The Sharing model of colleges and universities union and regions}

A university union or regional universities alliance and the standardized education resources public service platform are necessary. The platform has the function of network video living broadcast and video resources co-construction and sharing. Teachers are encouraged to make video resources at different levels in the way of collaboration or division and cooperating with relevant industries and enterprises strictly with the relevant technical standards of video resources production. It is suggested to carry out effective and incentive mechanism, ensure knowledge property according to the workload, quality and responsibilities of different colleges and universities in funding. The quality and schedule are evaluated and supervised by relevant departments in charge. The completed video resources are shared within the organization and regional colleges and universities through the standardized .Other institutions and social individual users can share these video resources by the way of registration authority or exchanges.

\section{Conclusion}

Video resources are built mainly at the material, curriculum and major levels on the basis of different disciplines and the feature of practice teaching in vocational colleges by university union or regional universities alliance along with relevant industries and enterprises. Video resources with systematic, integrity, pertinence and pervasive characteristics are shared through public platforms. The shared video resources improve the utilization rate of video resources, play an important role in the practical teaching, improve the quality of teaching and push practice teaching connotation construction and practice teaching reform in higher vocational education.

\section{References}

[1]Yu Zhongwen, Liu Shouyi, Zhu Fanglai,The practice of higher occupation technique education teaching research,first ed.Beijing, 2004 .

[2]Huang Qiongzhen, Huang Ying,Discussion on the mechanism of the co-construction and sharing of network education resources of University, Higher Education Exploration, Vol.131(2010)60-63.

[3]Li Gengliang, Some problems should pay attention in the process of co-construction and sharing of the digital educational information resources, education and teaching research,Vol.23, (2009)37-39.

[4]Liu Weihan,The mechanism of co-construction and sharing of network education resources, Modern Information,Vol.17(2007)161-162.

[5]Yang Xinghua, Yuan Feng, Wang Yingchun, Thinking and practicing in practical teaching resources co-construction and sharing, Vocational technical Education. Vol.32,(2011)58-60.

[6] Zhang Penggao,Xie Xiaoyu.To develop interactive video teaching so as to explore new mode of co-construction and sharing, Education Information of China,Vol.20(2011)4-5. 